TI 2011-102/3

Tinbergen Institute Discussion Paper

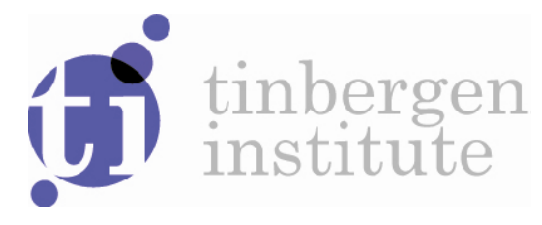

\title{
Trade-offs between Different Early Childhood Interventions: Evidence from Ecuador
}

José Rosero'

Hessel Oosterbeek ${ }^{2}$

Faculty of Economics and Business, University of Amsterdam, and Tinbergen Institute. 
Tinbergen Institute is the graduate school and research institute in economics of Erasmus University Rotterdam, the University of Amsterdam and VU University Amsterdam.

More TI discussion papers can be downloaded at http://www.tinbergen.nl

Tinbergen Institute has two locations:

Tinbergen Institute Amsterdam

Gustav Mahlerplein 117

1082 MS Amsterdam

The Netherlands

Tel.: +31(0)205251600

Tinbergen Institute Rotterdam

Burg. Oudlaan 50

3062 PA Rotterdam

The Netherlands

Tel.: +31(0)10 4088900

Fax: +31(0)104089031

Duisenberg school of finance is a collaboration of the Dutch financial sector and universities, with the ambition to support innovative research and offer top quality academic education in core areas of finance.

DSF research papers can be downloaded at: http://www.dsf.nl/

Duisenberg school of finance

Gustav Mahlerplein 117

1082 MS Amsterdam

The Netherlands

Tel.: +31(0)20 5258579 


\title{
Trade-offs between different early childhood interventions: Evidence from Ecuador*
}

\author{
José Rosero Hessel Oosterbeek
}

\begin{abstract}
Using a discontinuity in the funding scheme, we evaluate the impact of home visits and child care centers on poor children and mothers in Ecuador. We find that home visits are beneficial for children's cognitive outcomes and health and for mothers' psychological well-being but reduce mothers' labor force participation. Child care centers cause almost the exact opposite effects. Results are consistent with a framework in which child outcomes are determined by the quantity and quality of time inputs and in which mother's well-being depends on working hours and child outcomes.
\end{abstract}

JEL-codes: J13, I28, H40, O12

Keywords: Early childhood development; child care centers; home visits; regression discontinuity design; developing country; Ecuador

\section{Introduction}

More than 200 million children under 5 years in developing countries are exposed to the risks of poverty, malnutrition, poor health and unstimulating home environments (Grantham-McGregor et al., 2007). This is supposed to be detrimental for the development of these children, which in turn contributes to low levels of education, low income and high fertility. Governments of developing countries and NGO's are aware of this vicious circle of poverty and allocate resources to preschool interventions with the aim to provide disadvantaged children in developing countries a better start (Engle et al., 2007).

Compared to the many studies dealing with early childhood programs in developed countries, little is known about the effects of such programs in the context of developing

*This version: July 2011. We thank Monique de Haan, Christina Felfe, Erik Plug and seminar participants in Amsterdam, Quito, Trondheim and Uppsala for their helpful comments. We acknowledge the financial support from the Ecuadorian government and the Inter-American Development Bank. The usual disclaimer applies. Both authors are affiliated with the University of Amsterdam and the Tinbergen Institute. E-mails: j.a.roseromoncayo@uva.nl; h.oosterbeek@uva.nl. 
countries. ${ }^{1}$ A few studies used randomized control trials to examine the impact of homebased or center-based interventions in developing countries. McKay et al. (1978) study a child care program aimed at deprived children in Colombia and find positive effects on cognitive ability. Waber et al. (1981) examine the effects of nutritional supplementation and/or a maternal education program, also in Colombia, on young children's cognitive development. Food supplementation boosts performance, especially on motoric sub-tests. Powell et al. (2004) find positive effects of a home visit program in Jamaica on children's cognitive outcomes.

Other studies rely on non-experimental approaches to address the potential endogeneity of treatment. Attanasio and Vera-Hernandez (2004) use distance to the nearest center as an instrumental variable to evaluate the effect of a nutrition and child care program in rural Colombia on children's nutritional status, school achievement and female labor supply. They find very large and positive impacts, especially for children from the poorest backgrounds. ${ }^{2}$ Behrman et al. (2004) apply a matching estimator to assess the impacts of a preschool program in Bolivia on child outcomes. Impacts are highly dependent on age and exposure duration. Significant positive effects on cognitive and psychosocial outcomes are found when exposure is at least 7 months. Berlinski and Galiani (2007) exploit variation across regions in facilities expansion, to examine the impact of construction of pre-primary school facilities in Argentina. They find a sizable impact on pre-primary school participation among children aged between 3 and 5. The implicit child care subsidy induced by the program also increases maternal employment. ${ }^{3}$

Our paper examines the impact of both child care centers and of home visits on a range of relevant outcomes of young children and their mothers from poor families in Ecuador. The largest organization that funds early childhood programs in Ecuador ranks proposals of prospective providers of such programs on the basis of a score which is a mixture of perceived quality of the providers and indicators of the social background of the families served by the program. The organization then allocates its available budget to the programs with the highest scores. This creates a discontinuity in the probability of treatment at the score where the available budget of the funding organization is exhausted.

We exploit this feature in a regression discontinuity design in which we instrument a child's exposure to treatment with a binary indicator that equals one if the child was

\footnotetext{
${ }^{1}$ Studies for developed countries include: Currie and Thomas (1995); Gormley, Jr. and Gayer (2006); Magnuson et al. (2007); Baker et al. (2008); Wong et al. (2008); Datta Gupta and Simonsen (2010); Felfe and Lalive (2010); Fitzpatrick (2010); Havnes and Mogstad (2011). Currie (2001) and more recently Almond and Currie (2011) survey this literature.

${ }^{2}$ Attanasio et al. (2010) extend the analysis to data from urban areas and use additional instrumental variables. Their results confirm the previous findings.

${ }^{3}$ In a related paper Berlinski et al. (2008) find that one year of pre-primary school increases average third grade test scores by $23 \%$ of the standard deviation. They also find effects on student's self-control, effort, class participation, and discipline.
} 
listed for a program that received a score at or above the cutoff score, and zero if the child was listed for a program that received a score below the cutoff score. In the analysis we control for the programs' underlying scores. This approach provides a credible source of exogenous variation to identify the effects of the two treatments relative to their respective control groups. Because prospective providers choose themselves whether to apply for funding for a child care center or for home visits, we combine the regression discontinuity design with a difference-in-differences approach (and matching) to compare the impacts of the two treatments.

Four features of this paper stand out. First, we evaluate and compare the impacts of two different early childhood interventions using the same sampling design, the same tests and questionnaires and the same estimation method. We are not aware of other studies doing so. Second, we consider a range of outcomes: children's cognitive and motor development, children's health, parenting styles, mothers' labor supply and income, and mothers' stress and depression. ${ }^{4}$ Looking at this broad range of outcomes gives a more complete picture of the effects of early childhood interventions. Also here, we are not aware of many other studies doing so. Third, in comparison to most other studies for developing countries, we collected data from a relatively large sample of over 2500 children and their mothers. Finally, we analyze a large scale national program instead of a small, tailor-made intervention.

Our results show that home visits have a positive impact on children's cognitive and motor outcomes, whereas child care centers appear to have no impact or even a negative impact on these outcomes. Home visits reduce the likelihood that children have anemia and have no impact on their weight for age and height for age. Child care centers, in contrast, increase the probability that children are underweight. Furthermore, home visits reduce mothers' depression and stress and make them more responsive towards their children. Child care centers do the opposite: they increase mothers' depression and stress and reduce responsiveness. Finally, child care centers increase mothers' labor market participation and family income, while home visits reduce mothers' labor market participation but leave family income unaffected. The two types of interventions thus represent a tradeoff between child outcomes and mother's psychological well-being on the one hand, and labor market participation and family income on the other hand.

Our findings are consistent with a framework in which children's outcomes are determined by the quantity and the quality of time spent with them by the mother and by the early childhood program, and in which the psychological well-being of the mother is determined by her working hours and the outcomes of the child. In this framework,

\footnotetext{
${ }^{4}$ Engle et al. (2007) draw attention to the fact that women in developing countries have high rates of stress and that many suffer from depressive symptoms.
} 
child outcomes and mother's psychological well-being are adversely affected by child care centers through the negative effect these centers have on the mother's parenting style and through the increase of mother's working hours. Home visits do not have adverse effects since this intervention improves mother's parenting styles and reduce her working hours.

Our findings regarding child care centers are in line with results recently reported by Baker et al. (2008) for Canada. Exploiting the introduction of universally accessible child care in the province of Quebec in a difference-in-differences framework, they find that child care use increases maternal labor supply but harms child outcomes in terms of aggression, motor and social skills and illness. Moreover, parenting becomes more hostile and less consistent, and parents' health worsens.

The paper proceeds as follows. The next section provides further details about the early childhood development programs in Ecuador and about the context. Section 3 discusses the empirical approach used to identify the programs' impacts and to compare these. Section 4 describes the sampling design and the scales on which various outcomes are measured. Section 5 provides descriptive statistics of the main variables used in the analysis and evidence that the groups above and below the funding threshold are not systematically different. Section 6 presents and discusses the empirical results. Section 7 presents a simple framework that helps to understand the coherence of our findings. Section 8 summarizes and concludes.

\section{Context and interventions}

\section{Context}

Ecuador is a lower-middle income country, characterized by high poverty levels and high inequality. Of its total population of 13 million people, 1.5 million are children between 0 to 5 years old. 650,000 of these young children live in families belonging to the poorest 40 percent of the country. The 40th percentile of the wealth distribution is the government's threshold level for cash transfers to poor families. According to Grantham-McGregor et al. (2007) Ecuador is (in 2004) among the four countries in South-America where 20 to 40 percent of children under 5 years are disadvantaged; the others are Peru, Bolivia and Paraguay. In the rest of South-America the percentage of disadvantaged children below age 5 is less than 20 percent.

Education in Ecuador starts when children are between 6 and 7 years old. Enrollment in primary school is almost universal, but drops sharply at the secondary school level (see Oosterbeek et al., 2008).

Early childhood development programs are offered by both private and public providers. 
Private provision is small and mainly targeted towards middle and high income families. Public provision primarily serves low income families. The public provision is targeted towards children in rural and marginal urban areas. There are three main public providers, the largest of these is FODI. ${ }^{5}$ FODI started in 2005 and currently serves around 300,000 children from poor families all around Ecuador.

\section{Programs}

FODI supports two types of programs: child care centers and home visits. One third of the children served by FODI attends a child care center, the other two thirds are exposed to home visits. The main objective of the programs is to improve the early development of young children from poor families. A program is provided at the community or neighborhood level. There is never more than one program per community/neighborhood.

Child care centers provide day care, nutrition (breakfast and lunch) and educational services. Day care is provided following a curriculum designed by FODI, 52 weeks per year, 5 days per week, and 8 hours per day. A trained teacher works with groups of 8 to 10 children. An average center serves 45 children in the age range of 0 to 6 years. The annual cost amounts to US\$ 488 per child. To put this amount into perspective, the average monthly income in our sample is US\$ 300 per family or US\$ 55 per capita. ${ }^{6}$ Parents do not pay a fee; FODI bears the full cost.

Through home visits, FODI attempts to stimulate children and to improve parents' attitudes, knowledge and behavior towards the development of their children. An important aim of the home visits is to teach mothers how to engage with their child in enriching activities, how to interact with their child in a non-aggressive way, how to create a responsive environment and how to prepare nutritional meals for their children. Children and their mother are treated individually when the child is younger than 3 and in groups when the child is above 3. Home visits last 1 hour per week. Advisers work according to guidelines set by FODI. The annual cost of this intervention is US\$ 109 per child. Also here, FODI bears the full cost, and parents are not charged.

Children who are not served by one of the programs - the control groups - are normally looked after by their mother or another family member (grandparents or older sibling) or a neighbor.

\footnotetext{
${ }^{5}$ FODI stands for "Fondo de Desarrollo Infantil". The other two large public providers are INNFA (for "Instituto del Nino y la Familia") and ORI (for "Operacion Rescate Infantil").

${ }^{6}$ In 2000, Ecuador adopted the US dollar as its official currency.
} 


\section{Selection process}

FODI does not run its own centers but subsidizes non-profit suppliers of early childhood development centers. FODI allocates its budget through a (beauty) contest. So far it organized such contests in 2005, in 2006 and in 2008. In this paper we use data from applicants (winners and losers) to the second (2006) contest. This contest was targeted to poor unserved neighborhoods or communities. The available budget for this contest was US\$ 12 million. 240 organizations submitted a proposal, 95 of which were awarded for a total coverage of 60,000 children. Awarded proposals initially receive funding for a two year period, which is normally renewed afterward.

In the 2006-contest, a proposal was only considered for funding if (i) it included a list with the names of the children it would serve if awarded, (ii) the area was not yet served by a public provider, and (iii) the proposal fulfilled certain standards regarding infrastructure and educators' skills. Proposals meeting these requirements were given a score based on five criteria (behind each criterion, the maximum number of points that can be earned for it): socioeconomic characteristics of the neighborhood (180); coherence of the proposal (130); share of outside funding (30); quality of personnel (150); financial aspects (110).

Adding the maximum scores per element gives an overall maximum score of 600 . FODI then allocated its available budget for the second contest by funding proposals from high to low until the budget was exhausted. In practice FODI spent the last dollar of the available budget on a proposal that received an overall score of $425 .^{7} 8$ We will exploit this funding threshold in a regression discontinuity design. The threshold could not be anticipated by the applicants or the organizers, reducing the likelihood of manipulation. The discontinuity applies at the level of proposals and not at the level of children listed in a proposal. There is no ranking of individual children within or across proposals.

\section{Empirical approach}

We are interested in the impact of exposure to child care centers and home visits on cognitive and physical outcomes of children, and on parenting styles, psychological well-being and labor market outcomes of their mothers. Naive OLS-regressions are likely to give biased estimates of these relationships due to (self-)selection of children and families into treatment. For instance, programs may specifically target their efforts towards children that would otherwise be severely deprived. Without intervention these children would

\footnotetext{
${ }^{7}$ Beforehand, a score of 400 was set as the minimum quality standard to be eligible for funding.

${ }^{8}$ The proposal with the lowest score that received funding was a proposal for a home visiting program, but the same cutoff score then applies to proposals for child care centers. All proposals for child care centers with a score above 425 received funding, while no proposal for child care centers with a score below 425 received funding.
} 
probably have worse outcomes than other children. Or likewise, parents may for some reason prefer to enroll their smarter children into preschool programs. Without exposure to a treatment these children would probably have better outcomes than other children.

The way in which FODI allocated its budget in the second contest provides a regression discontinuity design which gives a source of exogenous variation which we will exploit to estimate the causal impacts of the two interventions. In practical terms the regression discontinuity design boils down to an instrumental variable approach in which the binary indicator $(Z)$ of having a score above or below the funding threshold is used as instrument for exposure to treatment. In this approach we can condition on a smooth function of the underlying score $(s)$ (referred to as the forcing variable) and other covariates $(X)$. This gives the following equation for home visits:

$$
Y_{i}=\alpha_{H V}+\delta_{H V} H V_{i}+f_{H V}\left(s_{i}\right)+X_{i} \beta_{H V}+\varepsilon_{H V i}
$$

where $H V=1$ if the child was exposed to home visits and $H V=0$ if the child was assigned to the comparison group for home visits. Likewise to evaluate the impact of child care centers we estimate:

$$
Y_{i}=\alpha_{C C}+\delta_{C C} C C_{i}+f_{C C}\left(s_{i}\right)+X_{i} \beta_{C C}+\varepsilon_{C C i}
$$

where $C C=1$ if the child was enrolled in a child care center and $C C=0$ for children assigned to the comparison group for child care centers.

The specification of the smooth function of the forcing variable can in some applications of the regression discontinuity design be a delicate choice. This is not the case in our application. In the main text we will present graphs based on linear regressions on both sides of the cutoff point (as recommended by Imbens and Lemieux, 2008) and estimates based on quadratic specifications of $f_{H V}(s)$ and $f_{C C}(s)$. In Tables A2-A4 in the appendix we present results based on other specifications (including a spline and a cubic). As our results will show, controlling for the forcing variable makes a difference, but the exact way in which this is done does not matter.

The identifying assumption in this framework is that conditional on covariates and the forcing variable, treatment is as good as random. In the equations, $H V_{i}$ and $C C_{i}$ are instrumented by $Z_{i}$, where $Z_{i}=1$ if $s_{i} \geq s_{0}$, and $Z_{i}=0$ if $s_{i}<s_{0}$, and where $s_{0}$ is the funding threshold of the overall score which for both programs equals 425 . The parameters of interest are $\delta_{H V}$ and $\delta_{C C}$. To avoid confusion, note that these parameters are estimated on different samples. The impact of home visits is estimated using a sample of children and their mothers who were on the list of a proposal for a home visit program, while the impact of child care centers is estimated using a sample of children and their 
mothers who were on the list of a proposal for a child care center program. ${ }^{9}$

The procedure of allocating funding allows us to compare outcomes of children and their mothers that were on the list of a proposal for a home visit center that received a score above the threshold to outcomes of children and their mothers that were on the list of a proposal for a home visit center that received a score below the threshold. It also allows us to compare outcomes of children and their mothers that were on the list of a proposal for a child care center that received a score above the threshold to outcomes of children and their mothers that were on the list of a proposal for a child care center center that received a score below the threshold. The regression discontinuity design does not allow us to compare the outcomes of children who were exposed to home visits with the outcomes of children who were exposed to child care centers. The reason is that (prospective) providers of early childhood development programs decide on the type of program they want to offer.

To make inferences about the relative effectiveness of the two types of programs we assume that the difference in outcomes between the two comparison groups measures the no-intervention difference for the two treatment groups. We can then apply a differencein-differences approach. The estimator for the impact of home visits relative to child care centers is then:

$$
(E[Y \mid H V=1]-E[Y \mid C C=1])-(E[Y \mid H V=0]-E[Y \mid C C=0])
$$

where $E[Y \mid x=1]$ is the average outcome for children exposed to treatment $x$, and $E[Y \mid x=$ $0]$ is the average outcome for children assigned to the comparison group of treatment $x$. In practice we implement this by estimating the following regression with instrumental variables:

$$
Y_{i}=\beta_{0}+\beta_{1} L H V_{i}+\beta_{2} T_{i}+\beta_{3} L H V_{i} \cdot T_{i}+f\left(s_{i}\right)+f\left(s_{i} \cdot L H V_{i}\right)+X_{i} \beta_{4}+L H V_{i} \cdot X_{i} \beta_{5}+\varepsilon_{i}
$$

where $L H V_{i}=1$ indicates that a child's name appeared on the list of a proposal submitted for funding as home visit program (whether they were treated or not), $L H V_{i}=0$ if the child's name appeared on the list of a proposal submitted for funding as child care center program. $T_{i}=1$ indicates exposure to one of the two programs, $T_{i}=0$ otherwise. $T_{i}$ and $L H V_{i} \cdot T_{i}$ are instrumented with $Z_{i}$ and $L H V_{i} \cdot Z_{i}$. Note that the effect of the forcing variable and of the control variables $X_{i}$ are allowed to vary between the two interventions. Ignoring covariates $\left(X_{i}\right), \beta_{1}$ is now the average difference in outcomes between children listed for child care centers and children listed for home visits in the absence of treatment, whereas $\beta_{2}$ is the average difference in outcomes between children in the control group and in the

\footnotetext{
${ }^{9} \mathrm{We}$ are thus also not using one single instrumental variable $Z$ to estimate two parameters.
} 
treatment group for child care centers. $\beta_{3}$ is the average difference in outcomes between children enrolled in child care centers and children exposed to home visits.

The estimate of $\beta_{3}$ can only be interpreted as the causal effect of exposure to home visits instead of placement in child care centers if the treatment effect is homogeneous. This excludes selection into programs on the basis of comparative advantage. This would for instance be the case if children exposed to home visits benefit more from home visits than children placed in child care centers. To examine the robustness of our findings, we estimate this difference-in-differences equation not only on the full sample, but also on a sample of observations with a very similar propensity to be on the list for home visits (instead of for a child care center). We implement this by first regressing the binary indicator for being on the list for home visits $(L H V)$ on observables $(X)$, then calculating for each observation its predicted probability to be on the list for home visits, and based on this restrict the sample to observations with a predicted probability that is within 1.06 standard deviation of the mean predicted probability. The value of 1.06 was chosen such that in this restricted sample the groups actually on the list for home visits and actually on the list for child care centers are not significantly different on any of the background variables that we include in the analysis. The leaves us with 68 percent of the original sample.

\section{Data}

A total of 113 submitted proposals passed the minimum quality requirement of 400 points. From these we selected all proposals with a score at most one standard deviation from the threshold. We thus start with a sample that can be regarded as a discontinuity sample (e.g. Angrist and Lavy, 1999). We subsequently selected a random sample of the centers that were included in these proposals. Recall that one proposal can include multiple centers. Within each center, we selected a random sample from the children whose names were on the list attached to the proposal. ${ }^{10}$ Notice that the lists with names of the children that would be served are vital for our design. Without those lists it is impossible to know which children would have been treated by the providers that did not receive funding.

The final sample consists of 2,572 children in 99 centers; 38 providing child care centers and 61 home visits. Table 1 shows the numbers of observations (children and centers) in our final sample by program (home visits and child care centers), age group (all, above 36 months, and below 60 months) and treatment eligibility. ${ }^{11}$ We present a

\footnotetext{
${ }^{10}$ The random sampling of centers and children was done to stay within the budget constraint of this research project.

${ }^{11}$ As we will show in Section 5 treatment eligibility and actual exposure to treatment are very highly correlated.
} 
Table 1. Number of children by program, eligibility and age (number of centers in parentheses)

\begin{tabular}{llccc}
\hline Program & Age & Non-eligible & Eligible & Total \\
\hline Home visits & all & $830(28)$ & $988(33)$ & $1818(61)$ \\
& age $>36$ months & $739(27)$ & $794(33)$ & $1533(60)$ \\
\multirow{3}{*}{ Child care centers } & age $<60$ months & $465(27)$ & $704(33)$ & $1169(60)$ \\
& all $>36$ months & $371(12)$ & $478(26)$ & $889(38)$ \\
& age $<60$ months & $194(12)$ & $421(26)$ & $792(37)$ \\
\end{tabular}

breakdown by age because some cognitive and motor tests are only validated for children older than 36 months while others are only validated for children younger than 60 months.

Teams of data collectors visited the homes of all children included in the final sample. They collected data from the children and their mothers and families through interviews with the mothers and through tests and measurements. Data were collected between September and December of 2008. At the moment of data collection, treated children in our sample have on average been exposed to treatment during 21 months. This is the same for child care centers and home visits.

We used standard and validated test instruments to measure the cognitive, motor and social-emotional development of children. Some tests are specific for children older than 36 months. These are the Spanish versions of the Peabody Picture Vocabulary test which measures receptive vocabulary (language), the Woodcock-Johnson-Munoz test which measures long term memory, and the Pegboard test which measures fine motor skills. For all children from 0 to 60 months old, we use the Nelson-Ortiz test which measures four dimensions of child development: language skill, gross motor skill, fine motor skill and social behavior.

Test scores are standardized by age. We normalized the scores on the Peabody, Woodcock and Pegboard tests to mean zero and standard deviation one. Impact estimates are thus expressed in standard deviation units. Scores on the Nelson Ortiz tests are binary: above or below the mean of the age group.

To measure children's physical development we use height for age and weight for age. Height for age is an indicator for long-term health outcomes, while weight for age more reflects short-term health conditions. We also took blood samples to measure the hemoglobin levels of the children to detect iron deficiency anemia. For the mothers we measure the following outcomes: the Center for Epidemiological Studies Depression (CES-D) scale to measure depression and psychological stress, the Home Observation for Measurement of the Environment (HOME) scale to measure responsiveness to children, and variables related to the labor market such as participation, working hours and income. 
The CES-D covers the main symptoms of depression and is derived from five validated depression scales. The score on the HOME test is based on the interviewer's evaluation of the mother's attitudes and behavior towards the child during the interview. We converted respondents' scores on the CES-D test and the HOME test to mean zero and standard deviation one, so that again impact estimates are measured in standard deviation units.

\section{First stage and identifying assumptions}

In this section we will first show that whether a proposal is above or below the funding threshold almost perfectly determines whether a child that is on the list of a proposal, is exposed to treatment. We then discuss the identifying assumption and provide evidence in support of it.

All proposals with a score above the threshold received funding from FODI and all proposed programs had been implemented at the moment of data collection. Likewise, none of the proposals with a score below the threshold received funding from FODI and none of these proposed programs have been implemented. At the proposal or program level, the allocation of FODI's budget thus represents a sharp regression discontinuity design; the score assigned to the proposal perfectly determines whether the proposal receives funding and whether the proposed program is implemented.

The sharp design at the proposal or program level translates into an almost sharp design at the level of children. Just a few children included in a proposal that received funding did not participate in the program, and also just a few children included in a proposal that did not receive funding participated in an(other) early childhood program. ${ }^{12}$ The almost perfect compliance with the assigned treatment status results in first stage estimates close to one. Table 2 shows this, for both interventions and for various specifications. ${ }^{13}$

As mentioned before, proposals with a score above 425 (on a scale from 0 to 600) were eligible for funding and proposals with a lower score were not eligible. Table 3 shows average values of the scores for proposed programs above and below the threshold in our sample, separately for home visits and for child care centers. The table also shows the average scores the proposed centers received on each of the five components of the total score. The main factors determining whether proposals for home visit centers ended up below the threshold are the quality of staff and financial aspects of the proposals (see column (3)). There is no significant difference with respect to the social economic background of the communities that are proposed to be served. Also for child care centers, the

\footnotetext{
${ }^{12}$ Two children did not participate in a home visit program while they should, 9 children did not participate in a child care center program while they should, 7 children participated in a home visit program while they should not, and 5 children participated in a child care center while they should not.

${ }^{13}$ Results are virtually identical when we control for higher order terms of rank.
} 
Table 2. First stage regressions

\begin{tabular}{|c|c|c|c|}
\hline & $(1)$ & $(2)$ & (3) \\
\hline \multicolumn{4}{|c|}{ Home visits } \\
\hline \multirow[t]{2}{*}{ Above threshold $(Z)$} & $0.990 * * *$ & $0.983 * * *$ & $0.980 * * *$ \\
\hline & $(0.003)$ & $(0.009)$ & $(0.008)$ \\
\hline$F$-test instrument & 93652 & 12171 & 13765 \\
\hline Number of children (programs) & $1818(60)$ & $1818(60)$ & $1818(60)$ \\
\hline \multicolumn{4}{|c|}{ Child care centers } \\
\hline Above threshold $(Z)$ & $\begin{array}{c}0.968 * * * \\
(0.020)\end{array}$ & $\begin{array}{c}0.980 * * * \\
(0.024)\end{array}$ & $\begin{array}{c}0.969 * * * \\
(0.029)\end{array}$ \\
\hline$F$-test instrument & 2427 & 1661 & 1165 \\
\hline Number of children (programs) & $889(38)$ & $889(38)$ & $889(38)$ \\
\hline \multicolumn{4}{|l|}{ Controls } \\
\hline rank & No & Yes & Yes \\
\hline$X$ & No & No & Yes \\
\hline
\end{tabular}

Note: Estimates from linear probability models of actual treatment on assigned treatment. Robust standard errors that are clustered at the program-level in parentheses. *** indicates significance at the $1 \%$-level. Background controls are the variables included in Table 4.

quality of the proposed staff is the main factor determining whether a proposal ends up above or below the threshold (see column (6)). Three other factors also show significant differences between proposal above and below the threshold, but the differences in points on these items are small. The final column of the table compares the scores of home visits versus child care center proposals. This shows that home visits are proposed for communities/neighborhoods with a higher social-economic status (and therefore collect fewer points for SES) than the communities/neighborhoods for which child care centers are proposed. This underscores the importance to balance the children listed for the two programs when we compare the two treatments. There are otherwise no significant differences in the scores that the proposals for child care centers and for home visits received. We are thus comparing two types of interventions that, at least according to this grading system, are of comparable quality.

The identifying assumption in the regression discontinuity design is that conditional on a smooth function of the underlying score and observables included in the analysis, there are no systematic unobserved differences between observations just below the threshold and observations just above the threshold. While this assumption cannot be tested, we can test whether observations above and below the threshold are not systematically different in terms of observable characteristics.

Table 4 shows the average values for important background variables separately for observations below and above the funding threshold and separately for the two programs. It also reports the $p$-values from a $t$-test for differences in means conditional on a second 
Table 3. Components of score

\begin{tabular}{lccccccc}
\hline Variable & \multicolumn{3}{c}{ Home visits (HV) } & \multicolumn{7}{c}{ Child care centers (CC) } & HV vs CC \\
& $s<425$ & $s \geqslant 425$ & $p$ & $s<425$ & $s \geqslant 425$ & $p$ & $p$ \\
& $(1)$ & $(2)$ & $(3)$ & $(4)$ & $(5)$ & $(6)$ & $(7)$ \\
\hline Total score & 416.33 & 452.82 & 0.000 & 408.05 & 447.05 & 0.000 & 0.020 \\
\multirow{2}{*}{ SES } & $(5.96)$ & $(13.82)$ & & $(7.25)$ & $(12.51)$ & & \\
& 173.04 & 172.58 & 0.781 & 177.92 & 174.23 & 0.004 & 0.003 \\
Co-funding & $(6.43)$ & $(6.39)$ & & $(2.58)$ & $(4.84)$ & & \\
Quality of staff & 25.91 & 25.70 & 0.910 & 20.67 & 23.46 & 0.002 & 0.749 \\
& $(7.21)$ & $(6.89)$ & & $(0.99)$ & $(4.06)$ & & \\
Coherence & 22.60 & 48.73 & 0.000 & 15.97 & 44.36 & 0.000 & 0.108 \\
& $(12.55)$ & $(10.29)$ & & $(14.51)$ & $(18.57)$ & & \\
Financial aspects & 107.45 & 110.72 & 0.194 & 108.10 & 114.19 & 0.078 & 0.251 \\
\multirow{2}{*}{$N$} & $(10.59)$ & $(8.03)$ & & $(10.68)$ & $(7.29)$ & & \\
& 87.34 & 95.10 & 0.003 & 85.41 & 90.81 & 0.118 & 0.763 \\
& $(8.87)$ & $(11.83)$ & & $(7.25)$ & $(9.79)$ & & \\
& 28 & 33 & & 12 & 26 & & 99 \\
\hline
\end{tabular}

order polynomial of the forcing variable. The $p$-values in columns (3) and (6) of Table 4 indicate that the characteristics of children eligible for treatment are in most cases not significantly different from the characteristics of children not eligible for treatment. There is only a systematic difference in age. ${ }^{14}$ In the samples of both programs eligible children are significantly younger than non-eligible children; the age gap is about 6 months. Part of this difference can be attributed to eligible children being interviewed earlier than noneligible children. But even after we correct for that, a significant difference remains. We have no explanation for this. It makes it important, however, to control in all analyses for age. ${ }^{15}$ Recall also that all outcome variables are standardized by age.

The last two columns of the table report the $p$-values for differences in characteristics between children whose name appeared on the list of a proposal for home visits and children whose name appeared on the list of a proposal for a child care center. This information is useful for our difference-in-differences approach in which we directly compare the effects of the programs. The results show that children listed for child care centers are significantly older than children listed for home visits. There also is a difference in social background between children listed for home visits and children listed for child care centers. This difference shows up in the schooling levels of the mother and of the household head, mother's language-score, household size and the wealth index. As we already saw in Table 3, home visits serve children from relatively better-off families.

\footnotetext{
${ }^{14}$ The differences between eligible and non-eligible children are also statistically significant for gender in the home visits program and for receipt of the cash transfer in the child care center program. The means of the these variables are, however, almost identical for eligible and non-eligible children.

${ }^{15} \mathrm{We}$ also redid all analyses including higher order terms of age. This does not change any of the results.
} 
Table 4. Differences by eligibility status

\begin{tabular}{|c|c|c|c|c|c|c|c|c|}
\hline \multirow[t]{2}{*}{ Variable } & \multicolumn{3}{|c|}{ Home visits (HV) } & \multicolumn{3}{|c|}{ Child care centers (CC) } & \multicolumn{2}{|c|}{$\mathrm{HV}$ vs $\mathrm{CC}$} \\
\hline & $\begin{array}{c}s<425 \\
\quad(1)\end{array}$ & $\begin{array}{c}s \geqslant 425 \\
(2)\end{array}$ & $\begin{array}{l}p \\
\text { (3) }\end{array}$ & $\begin{array}{c}s<425 \\
\quad(4)\end{array}$ & $s \geqslant 425$ & $\begin{array}{l}p \\
(6)\end{array}$ & $\begin{array}{l}\text { All } \\
\text { (7) }\end{array}$ & $\begin{array}{c}\text { Balanced } \\
\text { (8) }\end{array}$ \\
\hline Boy (dummy) & $\begin{array}{c}0.52 \\
(0.50)\end{array}$ & $\begin{array}{c}0.51 \\
(0.50)\end{array}$ & 0.050 & $\begin{array}{c}0.50 \\
(0.50)\end{array}$ & $\begin{array}{c}0.52 \\
(0.50)\end{array}$ & 0.274 & 0.743 & 0.626 \\
\hline Age in months & $\begin{array}{c}55.8 \\
(14.4)\end{array}$ & $\begin{array}{c}49.6 \\
(12.9)\end{array}$ & 0.000 & $\begin{array}{c}58.3 \\
(14.3)\end{array}$ & $\begin{array}{c}52.0 \\
(12.4)\end{array}$ & 0.002 & 0.055 & 0.631 \\
\hline Household size & $\begin{array}{c}4.87 \\
(1.71)\end{array}$ & $\begin{array}{c}4.85 \\
(1.71)\end{array}$ & 0.437 & $\begin{array}{c}5.70 \\
(1.97)\end{array}$ & $\begin{array}{c}5.25 \\
(2.00)\end{array}$ & 0.245 & 0.026 & 0.721 \\
\hline Urban (dummy) & $\begin{array}{c}0.70 \\
(0.46)\end{array}$ & $\begin{array}{c}0.66 \\
(0.48)\end{array}$ & 0.934 & $\begin{array}{c}0.49 \\
(0.50)\end{array}$ & $\begin{array}{c}0.40 \\
(0.49)\end{array}$ & 0.802 & 0.088 & 0.612 \\
\hline Cash transfer (dummy) & $\begin{array}{c}0.58 \\
(0.50)\end{array}$ & $\begin{array}{c}0.55 \\
(0.50)\end{array}$ & 0.388 & $\begin{array}{c}0.61 \\
(0.49)\end{array}$ & $\begin{array}{c}0.58 \\
(0.49)\end{array}$ & 0.036 & 0.460 & 0.501 \\
\hline Wealth index & $\begin{array}{c}0.61 \\
(2.33)\end{array}$ & $\begin{array}{c}0.02 \\
(3.17)\end{array}$ & 0.661 & $\begin{array}{l}-2.16 \\
(3.58)\end{array}$ & $\begin{array}{l}-0.30 \\
(2.74)\end{array}$ & 0.349 & 0.069 & 0.899 \\
\hline Mother's age (years) & $\begin{array}{c}30.7 \\
(8.56)\end{array}$ & $\begin{array}{c}30.5 \\
(8.12)\end{array}$ & 0.847 & $\begin{array}{c}31.6 \\
(8.46)\end{array}$ & $\begin{array}{c}30.6 \\
(7.96)\end{array}$ & 0.109 & 0.283 & 0.884 \\
\hline Schooling mother (yrs) & $\begin{array}{c}7.24 \\
(3.66)\end{array}$ & $\begin{array}{c}7.61 \\
(4.13)\end{array}$ & 0.421 & $\begin{array}{c}5.38 \\
(3.55)\end{array}$ & $\begin{array}{c}5.96 \\
(3.56)\end{array}$ & 0.375 & 0.000 & 0.108 \\
\hline Schooling head (yrs) & $\begin{array}{c}6.66 \\
(3.87)\end{array}$ & $\begin{array}{c}6.72 \\
(5.36)\end{array}$ & 0.968 & $\begin{array}{c}5.51 \\
(3.50)\end{array}$ & $\begin{array}{c}5.74 \\
(3.37)\end{array}$ & 0.854 & 0.006 & 0.405 \\
\hline Language score mother & $\begin{array}{c}72.1 \\
(23.9)\end{array}$ & $\begin{array}{c}70.5 \\
(26.2)\end{array}$ & 0.994 & $\begin{array}{l}59.78 \\
(26.0)\end{array}$ & $\begin{array}{c}62.2 \\
(25.1)\end{array}$ & 0.398 & 0.016 & 0.642 \\
\hline Father present & $\begin{array}{c}0.72 \\
(0.45)\end{array}$ & $\begin{array}{c}0.81 \\
(0.39)\end{array}$ & 0.436 & $\begin{array}{c}0.83 \\
(0.38)\end{array}$ & $\begin{array}{c}0.77 \\
(0.42)\end{array}$ & 0.154 & 0.324 & 0.903 \\
\hline Mother present & $\begin{array}{c}0.95 \\
(0.22)\end{array}$ & $\begin{array}{c}0.96 \\
(0.21)\end{array}$ & 0.721 & $\begin{array}{c}0.95 \\
(0.23)\end{array}$ & $\begin{array}{c}0.96 \\
(0.19)\end{array}$ & 0.940 & 0.734 & 0.968 \\
\hline$N$ & 830 & 988 & & 411 & 478 & & 2707 & 1837 \\
\hline
\end{tabular}

Note: Mean values and standard deviations in parentheses. $p$-values are based on $t$-tests for equality of means. In columns (3) and (6) these are conditional on a second degree polynomial in the score. 
Because of the differences between the groups targeted by the two interventions, we constructed a balanced sample. On the basis of a linear probability model we estimated for each observation the probability to be listed for home visits instead of a place in a child care center. ${ }^{16}$ We then restricted the sample to observations for which the predicted probability to be listed for home visits differs at most 1.06 standard deviation from the mean probability to be listed for home visits. The remaining sample covers 68 percent of the observations from the original sample. The final column in the table shows $p$ values for differences in characteristics between children actually listed for home visits and children actually listed for a child care center in this balanced sample. This shows that these groups are not significantly different in any of the characteristics included in the analysis. ${ }^{17} 18$

\section{Results}

This section is divided into three subsections. The first subsection presents results for children's cognitive outcomes. The second subsection presents results for children's health outcomes. The final subsection presents results for mothers' outcomes. In each subsection we start with a graphical presentation of the results. We then present and discuss estimates of the impact of the two interventions on the various outcomes. For each set of outcomes there is also a table in the appendix which presents results from alternative specifications.

\subsection{Children's cognitive and motor outcomes}

Figure 1 shows for four different cognitive outcomes the relation between the rank of the proposed center and the cognitive outcome. Each hollow circle in a graph represents the mean outcome of the children that were on the list of the same center for home visits or child care. The size of each circle is proportional to the number of children that were listed for that center in the proposal. The solid lines represent the best linear fits through the hollow circles, where we weighted by number of children. These lines are drawn separately below and above the threshold value of 425 . Below each graph we report an estimate of the discontinuity at the threshold, with its standard error. These estimates come from regressions that allow for separate linear relations in rank at both sides of the threshold and include no other control variables.

\footnotetext{
${ }^{16}$ The results are reported in Table A1 in the appendix.

${ }^{17}$ When we broaden the sample to at most 1.07 standard deviation from the mean, mother's education starts to be significantly different between the groups.

${ }^{18}$ This restriction of the sample is similar in spirit to propensity score matching. The advantage of this procedure is that we can still use the regression discontinuity design.
} 
Figure 1. Relation between cognitive outcomes and rank by type of intervention
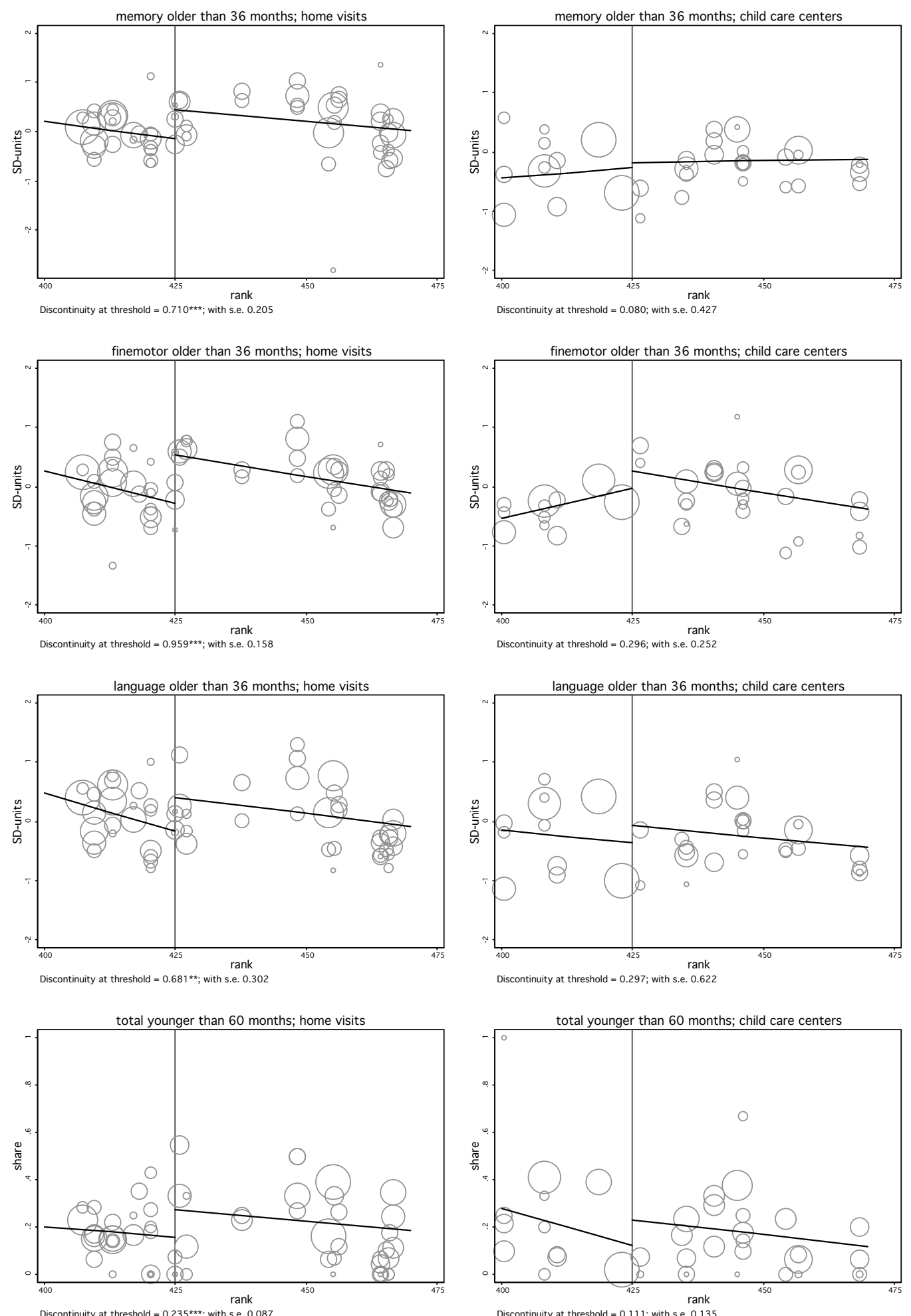

Note: Each hollow circle in a graph represents the mean value of the outcome value in a unit for home visits/childcare centers. The size of a circle is proportional to the number of children in the unit. The solid lines represent the linear best fits through the circles (weighted by circle size), separately below and above the threshold rank of 425. "total" in the bottom graphs is the average of gross motor, fine motor, language and social. 
The first thing to note from the graphs is that the relationship between rank and outcomes is not very systematic or strong, in most cases the slopes of the solid lines are not significantly different from zero. For most outcomes this relation tends to be negative, also for the proposals that received funding. Recall that the rank of a proposal is also determined by the social economic status of the community it intends to serve, where the rank increases when the community is poorer.

The graphs for the home visits intervention (on the left hand side of the figure) show increases in the cognitive scores around the discontinuity. The solid line right of the discontinuity starts at a higher level than where the solid line left of the discontinuity ends. In all cases the discontinuities at the threshold are significantly different from zero. The picture is less clear in the graphs for child care centers (on the right hand side of the figure). For all four measures the discontinuities at the thresholds indicate an increase in the score, but these increases are never significantly different from zero.

We further investigate this in Table 5, which reports various estimates of the impact of the two interventions for all cognitive and motor outcomes that were measured. The first three columns relate to tests administered for children older than 36 months and the last five columns relate to tests administered for children younger than 60 months. The top panel presents the impacts of home visits (versus no intervention) and the middle panel presents the impacts of child care centers (also versus no intervention). These results are IV-estimates based on equations (1) and (2), respectively. Results are given for two specifications; the first only includes controls for linear and quadratic terms of rank, while the second controls for the linear and quadratic terms of rank and background characteristics. ${ }^{19}$

The results for home visits in the top panel reveal the same clear pattern as Figure 1. Home visits have a positive impact on most outcomes and in both specifications. Focusing on the specification with covariates all estimates for children older than 36 months as well as the overall score of the tests for children under 60 months show a significant improvement of cognitive outcomes for children exposed to home visits. The impact sizes are substantial. The first three outcomes are measured in standard deviation units, hence the impacts vary between 39 and 85 percent of a standard deviation. The last five outcomes are measured as the probability to be above the mean score of the age group. The overall score goes up by almost 21 percentage points, relative to a base of 17 percent.

Without control variables, most of the estimates of the impact of child care centers on cognitive achievement are rather imprecisely estimated and none of the estimates is significantly different from zero. With control variables the estimates become more pre-

\footnotetext{
${ }^{19}$ In Table A2 in the Appendix we report results for other specifications, including a spline in rank, a linear specification and a cubic specification. Results are very similar.
} 


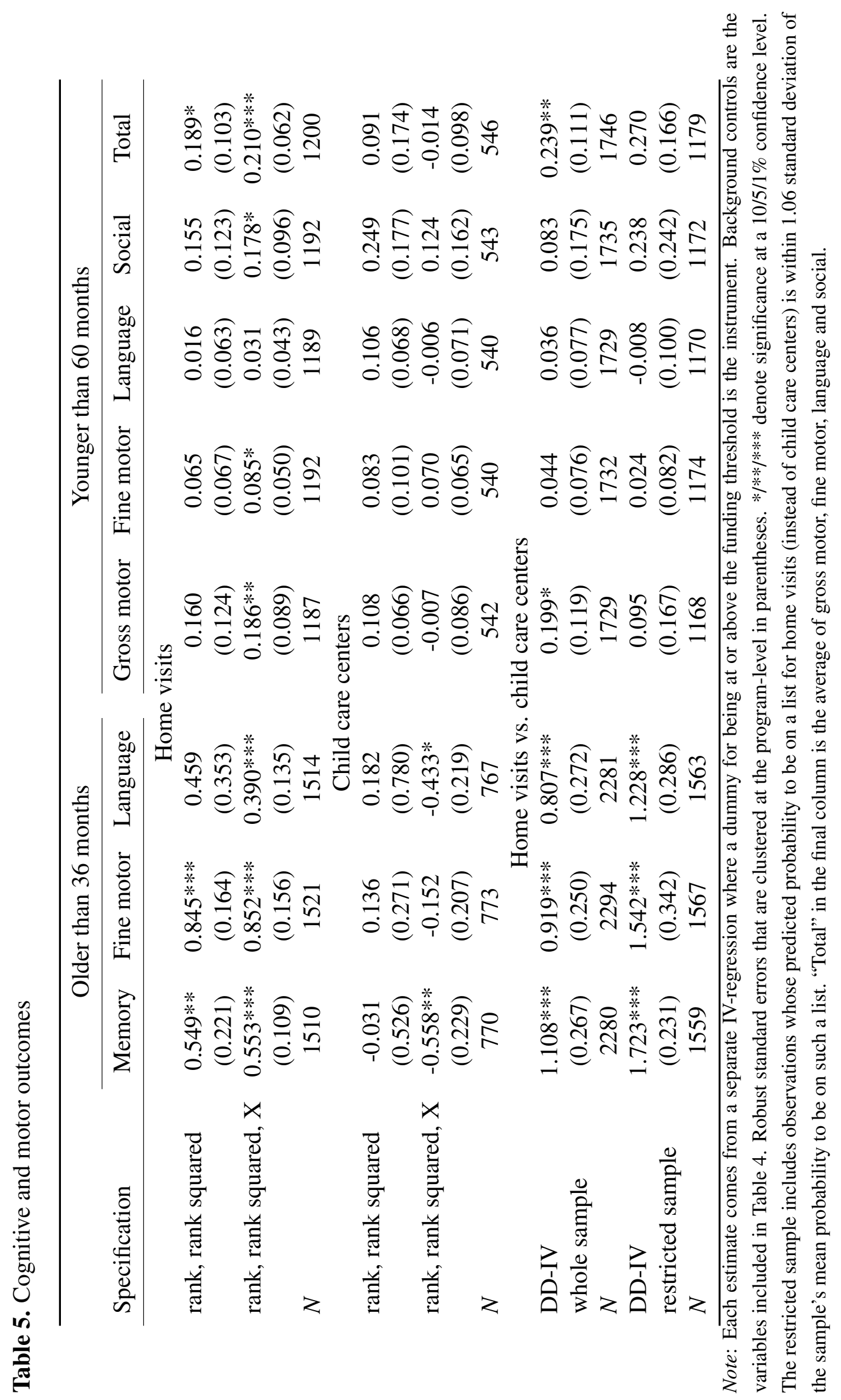


cise. Two of the estimates for children above 36 months are now significantly negative, indicating that children who have been exposed to child care centers do worse than the children who were listed for such centers but were not exposed to them. The other estimates are not significantly different from zero and often small in absolute size. Taken together, there is no indication of a positive impact of child care centers on the cognitive and motor outcomes of young children. If anything, the results suggest that child care centers harm the cognitive development of children above 36 months. ${ }^{20}$ We also inquired whether impacts are different for boys than for girls, and for children above and below 24 months old. Neither for home visits nor for child care centers, do we find any evidence for heterogeneity of impacts across these groups.

The bottom panel in Table 5 shows difference-in-differences estimates based on equation (3) to compare the impacts of home visits relative to the impacts of child care centers. The first set of results is based on the entire sample, while the second set of results is based on the balanced $(68 \%)$ sample of observations that have a similar predicted probability to be listed for home visits. While results vary somewhat across the two samples, the findings point in the same direction: children's cognitive and motor development benefits more from home visits than from child care centers. The effects are quite substantial. For instance, being exposed to home visits instead of attending a child care center increases the memory score by more than one standard deviation unit.

\subsection{Children's health outcomes}

We next look at the impact of the programs on children's health outcomes. Figure 2 shows the relationships between rank and the three health outcomes: anemia, underweight and below height. The two graphs at the top of the figure reveal a clear picture: the share of children with anemia drops sharply around the threshold value of rank for the home visits intervention and it increases slightly for the child care center intervention. The discontinuity at the threshold is significantly different from zero for the home visits, but not for the child care centers. For underweight and below height, the graphs reveal only small discontinuities at the thresholds and these are not significantly different from zero.

Further results are presented in Table $6 .{ }^{21}$ According to the specification with control variables, home visits reduce the incidence of anemia by 16 percentage points. Relative to a base of 0.46 , this implies a reduction in anemia by about one third. The impact of home visits on weight for age and height for age are small and not significantly different from zero. This contrasts with the impact of child care centers on children's health. Attendance

\footnotetext{
${ }^{20}$ The negative impact on language score for children older than 36 months disappears when a cubic term of rank is included; see Table A2 in the appendix.

${ }^{21}$ Results for other specifications are presented in Table A3 in the appendix.
} 
Figure 2. Relation between health outcomes and rank by type of intervention
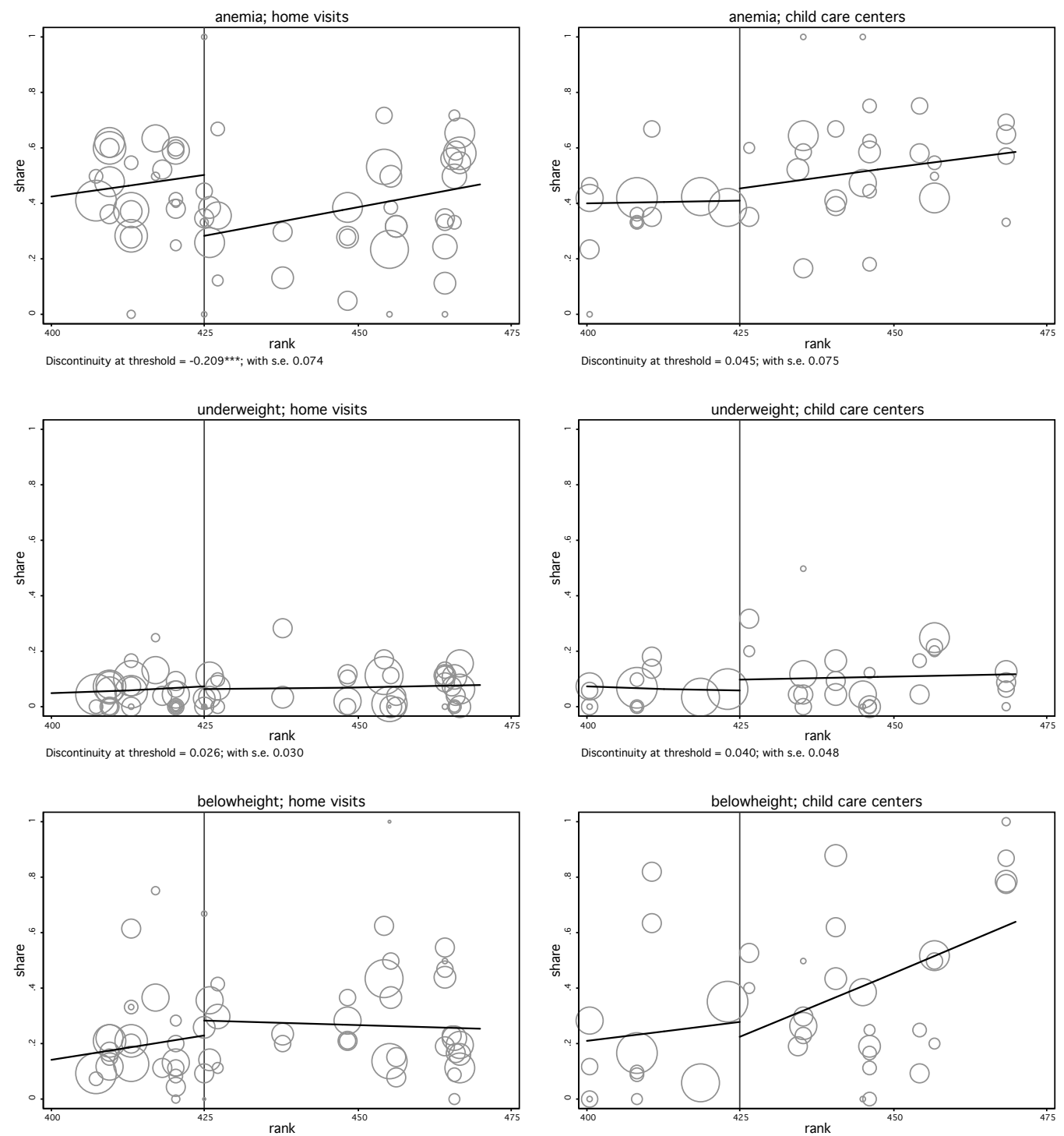

Discontinuity at threshold $=0.087$; $\begin{array}{r}\text { with s.e. } \\ 0.064\end{array}$ Discontinuity at threshold $=-0.057$; $\begin{gathered}\text { with s.e. } 0.144 \\ \text { ank }\end{gathered}$

Note: Each hollow circle in a graph represents the mean value of the outcome value in a unit for home visits/childcare centers. The size of a circle is proportional to the number of children in the unit. The solid lines represent the linear best fits through the circles (weighted by circle size), separately below and above the threshold rank of 425 . 
Table 6. Health outcomes

\begin{tabular}{|c|c|c|c|}
\hline Specification & Anemia & $\begin{array}{l}\text { Under } \\
\text { weight }\end{array}$ & $\begin{array}{l}\text { Below } \\
\text { height }\end{array}$ \\
\hline \multicolumn{4}{|c|}{ Home visits } \\
\hline \multirow[t]{2}{*}{ rank, rank squared } & $-0.157 * *$ & 0.030 & 0.050 \\
\hline & $(0.075)$ & $(0.028)$ & $(0.067)$ \\
\hline \multirow[t]{2}{*}{ rank, rank squared, $X$} & $-0.163 * *$ & 0.023 & 0.036 \\
\hline & $(0.067)$ & $(0.029)$ & $(0.060)$ \\
\hline$N$ & 1658 & 1787 & 1769 \\
\hline \multicolumn{4}{|c|}{ Child care centers } \\
\hline \multirow[t]{2}{*}{ rank, rank squared } & 0.055 & 0.051 & 0.006 \\
\hline & $(0.072)$ & $(0.048)$ & $(0.156)$ \\
\hline \multirow[t]{2}{*}{ rank, rank squared, $X$} & -0.017 & $0.097 * * *$ & 0.040 \\
\hline & $(0.103)$ & $(0.034)$ & $(0.077)$ \\
\hline$N$ & 763 & 872 & 870 \\
\hline \multicolumn{4}{|c|}{ Home visits vs. child care centers } \\
\hline DD-IV & -0.145 & $-0.087 * *$ & -0.025 \\
\hline (whole sample) & $(0.121)$ & $(0.041)$ & $(0.093)$ \\
\hline$N$ & 2421 & 2659 & 2639 \\
\hline DD-IV & -0.166 & -0.050 & -0.062 \\
\hline (restricted sample) & $(0.152)$ & $(0.062)$ & $(0.166)$ \\
\hline$N$ & 1654 & 1810 & 1799 \\
\hline
\end{tabular}

Note: See the note of Table 5.

to child care centers has no impact on the incidence of anemia or being below height, but it increases the probability of being underweight by 9.7 percentage points (relative to a baseline of 0.06), thereby reflecting short-term health problems such as diarrhea. The bottom panel presents estimates from the difference-in-differences specifications to compare the two treatments. While the estimates all point into the direction that home visits have a more favorable impact on children's health than child care centers, none of these differences is statistically significant.

\subsection{Mothers' outcomes}

Early childhood interventions potentially also have an impact on the way mothers interact with their children and on mothers' psychological well-being and labor market outcomes. Figures 3 and 4 show for each intervention the relations between rank and mothers' outcomes. The two graphs in the top of Figure 3 indicate that home visits reduce nonresponsive behavior of mothers towards their children, while child care centers provoke such behavior. The discontinuities at the thresholds are significant at the $1 \%$-level in both graphs. 
The second pair of graphs in Figure 3 indicate that mothers are more likely to read with their children when they have been exposed to home visits or when their children have been enrolled in child care centers. The discontinuities at the thresholds are, however, not significantly different from zero. For presence of learning materials in the home the discontinuities at the thresholds are not significant. The final pair of graphs in the figure indicates that home visits reduce mothers' stress and depression while child care centers lead to an increase of these symptoms. The discontinuity at the threshold is significantly different from zero in the graph for home visits.

The estimation results presented in columns (1) to (4) of Table 7 confirm the results from the graphs. ${ }^{22}$ Focusing on the results from the specification with controls for background characteristics, we find that home visits make mothers' more responsive to their children, while child care centers reduce responsiveness. The dependent variable here is measured in standard deviation units, so home visits increase responsiveness by half a standard deviation unit, while child care centers decrease it by almost one standard deviation unit. Being exposed to home visits has no impact on mothers reading to their children or the children having learning materials (books, clay, toys) at home. Attending a child care center has no significant impact on mothers reading to their children but it reduces the probability of having learning materials at home. The fourth column confirms that home visits reduce stress and depression in mothers whereas child care centers have the opposite impact. Effects are again in standard deviation units, implying that home visits reduce stress and depression by 30 percent of a standard deviation while child care centers increase it by over 40 percent of a standard deviation. These impacts are quite substantial.

The results in the bottom panel of the table show that these findings also hold when we compare the two treatments directly: when the child is exposed to home visits instead of a child care center, mothers are more responsive and their psychological well-being improves considerably.

Figure 4 shows for both interventions the relations between the forcing variable and labor market outcomes. The two graphs at the top of this figure clearly suggest that home visits reduce the incidence of mothers working, while child care centers increase this. The discontinuities at the thresholds are significantly different from zero. A similar pattern is observed in the second pair of graphs for the number of hours that the mother works. Again the discontinuities at the thresholds are significantly different from zero. The pair of graphs for the income of mothers is consistent with this. Mothers' income goes down in case of home visits while it increases when the child is enrolled in a child care center. Here only the discontinuity at the threshold in the graph for child care centers is

\footnotetext{
${ }^{22}$ See also Table A4 in the appendix for results from alternative specifications. Almost all results we report in Table 7 are robust to changes in the specification. When this is not the case, we mention that in the main text.
} 
Figure 3. Relation between mothers' outcomes and rank by type of intervention
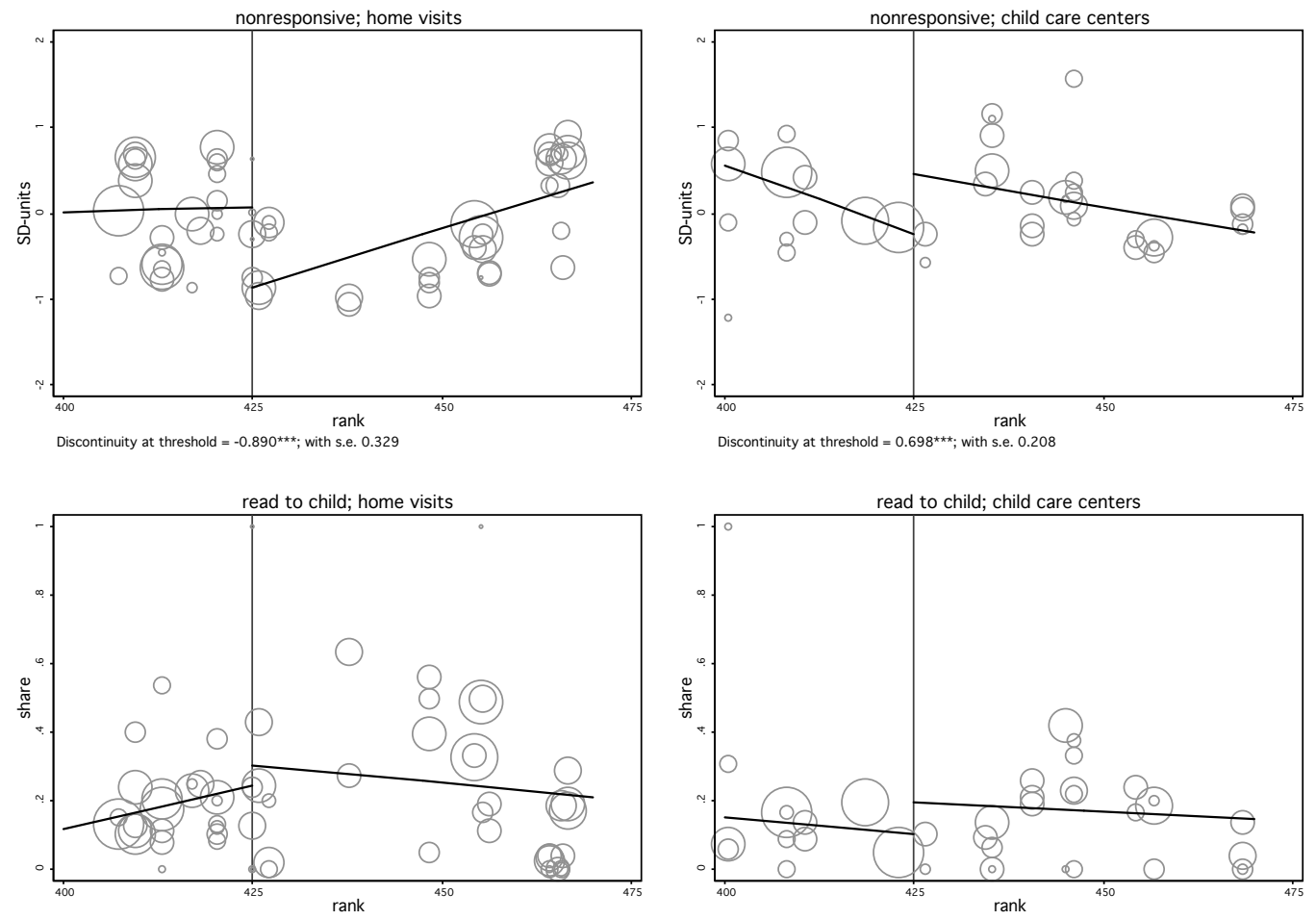

Discontinuity at threshold $=0.129$; with

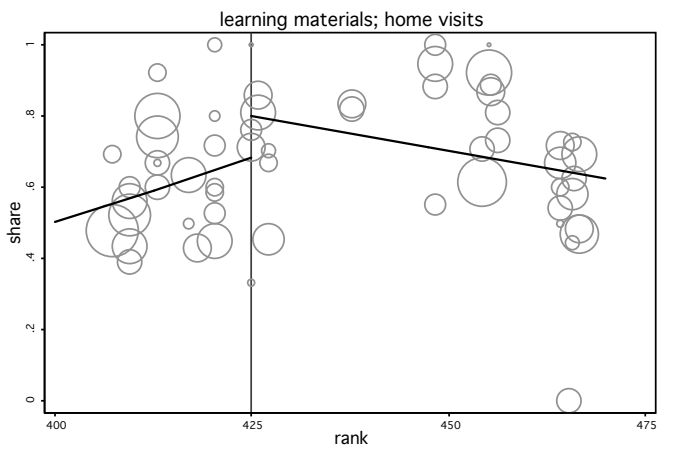

Discontinuity at threshold $=0.093$; with s.e. 0.077

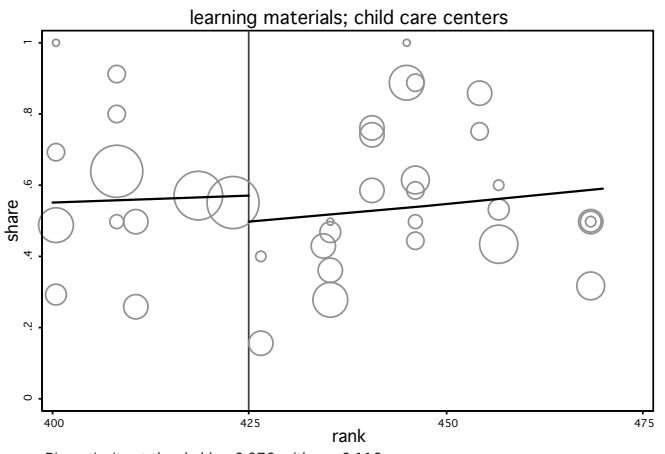

Discontinuity at threshold $=0.131$; with s.e. 0.110

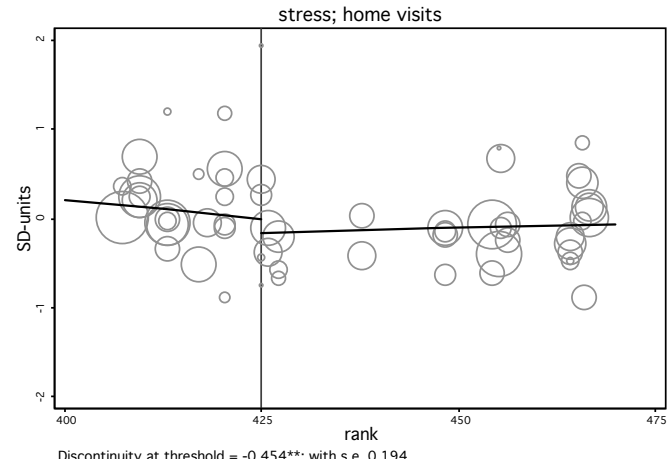

Discontinuity at threshold $=-0.076$; with s.e. 0.116

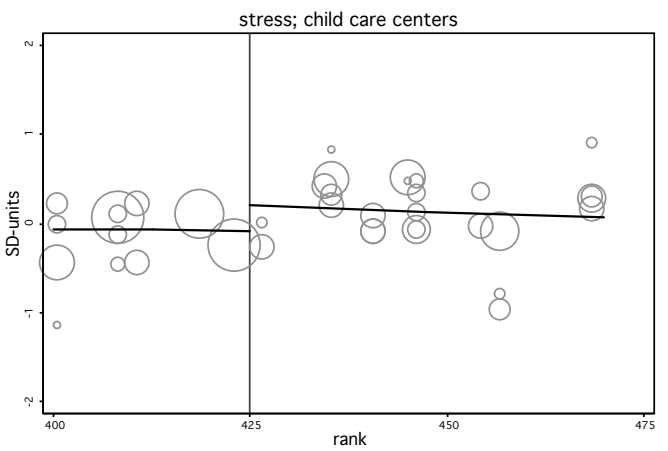

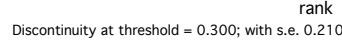

Note: Each hollow circle in a graph represents the mean value of the outcome value in a unit for home visits/childcare centers. The size of a circle is proportional to the number of children in the unit. The solid lines represent the linear best fits through the circles (weighted by circle size), separately below and above the threshold rank of 425 . 


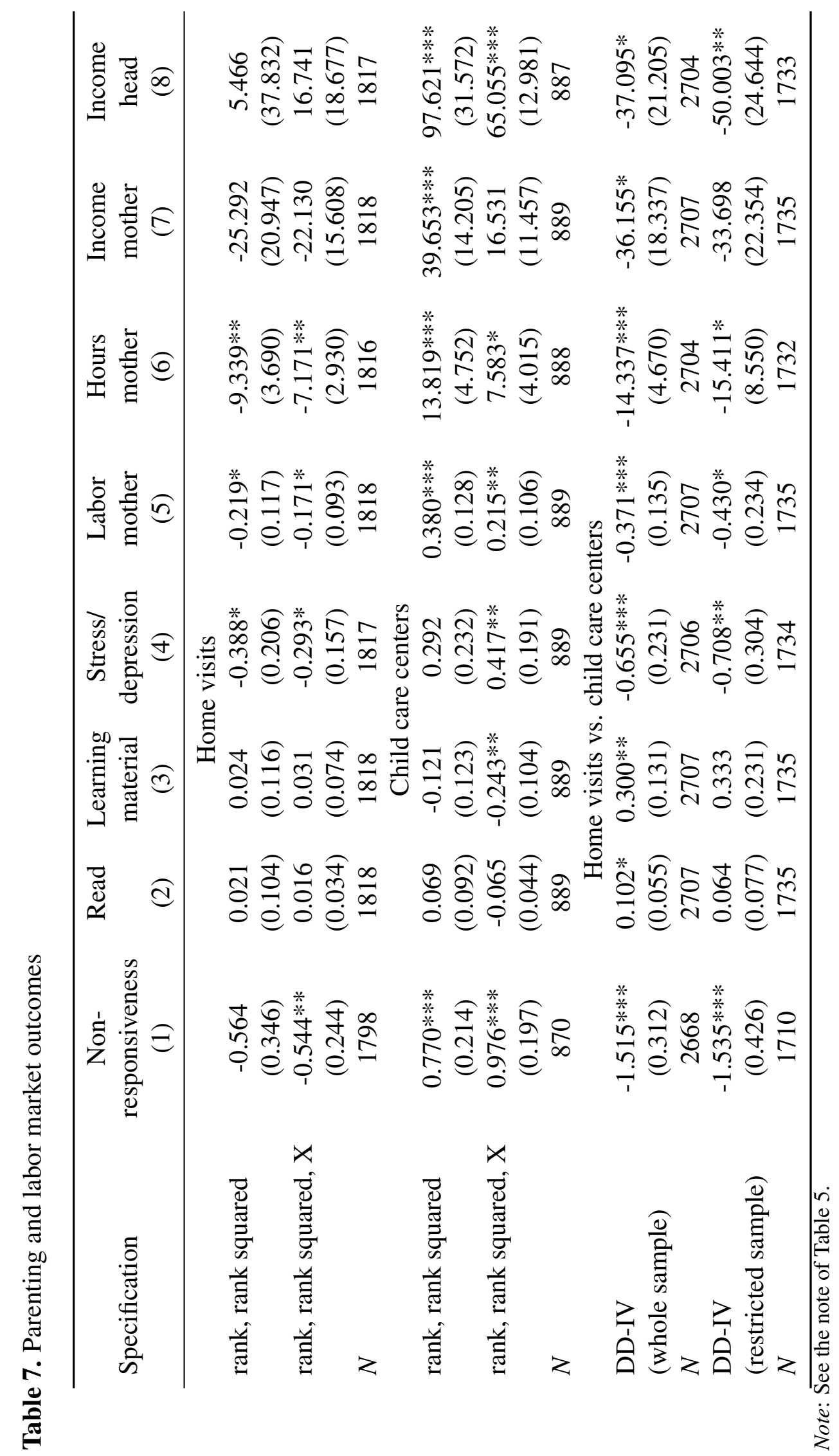


statistically significant. The final pair of graphs in the figure demonstrate the relationship with the income generated by the head of the household. For both interventions, we see a tendency for household heads to earn more when their child is exposed to an early childhood program, but the discontinuity is only significant at the threshold for child care centers.

The estimation results presented in columns (5) to (8) of Table 7 are consistent with the picture that arises from the graphs. We find a significantly positive effect of child care centers on the probability that the mother works. The effect is large; 22 percentage points in the specification with controls for background characteristics. Home visits achieve almost exactly the opposite. When children are served by home visits, their mothers are 17 percentage point less likely to work. For working hours we find that these go up by around 7 hours per week when the child is enrolled in a child care center, while these go down by the same number of hours in case of home visits. For income of the mother and the household head, we find insignificant effects of home visits. The effect of child care centers on income of the mother is positive but not significant in the specification that includes controls for background characteristics, and significantly positive for the income of the household head. It may seem strange that while women work more, not they but their husbands earn more. This is, however, not so strange in the context of a developing country with a large informal sector and where many families work in small household enterprises. Household income increases with around 80 USD per month. The bottom rows of the table show that the effects obtained from the regression discontinuity designs carry over to the direct comparison of home visits and child care centers.

\section{Putting the pieces together}

The previous section presented impact estimates of home visits and child care centers on a range of outcomes. Some outcomes are potentially affected by other outcomes. For instance, the mother's psychological well-being may be affected by the outcomes of the child. In this section we present a simple model that captures how various outcomes interrelate. We focus on three endogenous outcomes: child outcome $y_{c}$ (either cognitive outcomes or health), mother's psychological well-being $p w b_{m}$, and mother's hours of work $h r s_{m}$.

Child outcomes are assumed to be determined by the quantity and the quality of time inputs from the mother and from an early childhood intervention. We abstract from nutrition and income as separate inputs. Mother's psychological well-being is influenced by the outcomes of the child and by the mother's hours of work. Mother's hours of work in turn depend on the type of early childhood intervention. The quantity of the mother's 
Figure 4. Relation between labor market outcomes and rank by type of intervention
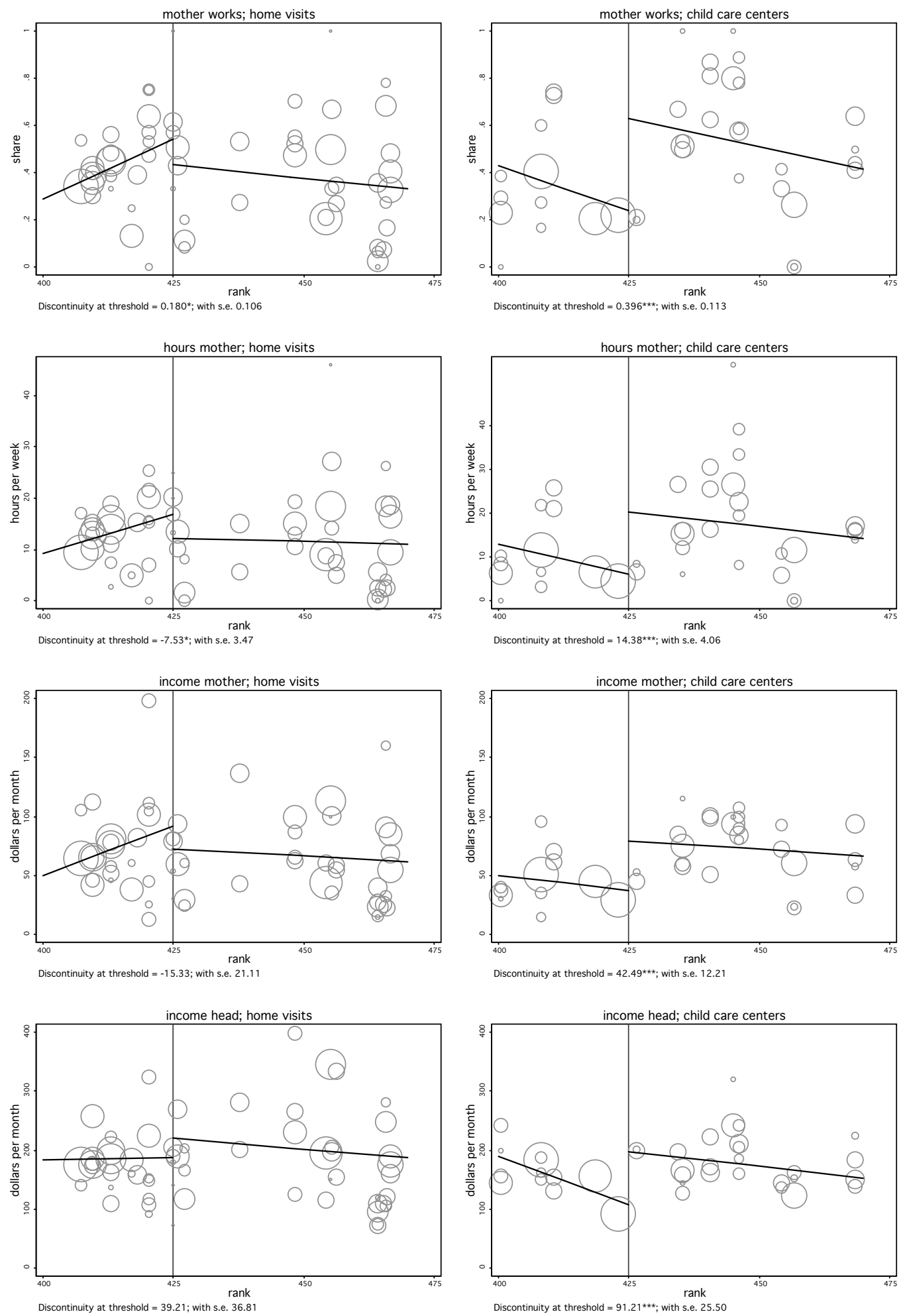

Note: See the note of Figure 1. 
time input $\left(q n t_{m}\right)$ depends on her hours of work and the quality of the mother's time input $\left(q l t_{m}\right)$ depends on her psychological well-being and the type of intervention ( $H V$ or $\left.C C\right)$. Obviously the quantity and quality of the time inputs $\left(q n t_{i n t}\right.$ and $\left.q l t_{i n t}\right)$ of the intervention depend on the type of intervention.

For simplicity we assume that all relations are linear. This gives the following seven equations

$$
\begin{aligned}
y_{c} & =a_{0}+a_{1} q n t_{m}+a_{2} q l t_{m}+a_{3} q n t_{i n t}+a_{4} q l t_{i n t} \\
p w b_{m} & =b_{0}+b_{1} y_{c}+b_{2} h r s_{m} \\
h r s_{m} & =c_{0}+c_{1} H V+c_{2} C C \\
q n t_{m} & =d_{0}+d_{1} h r s_{m} \\
q l t_{m} & =e_{0}+e_{1} p w b_{m}+e_{2} H V+e_{3} C C \\
q n t_{i n t} & =f_{0}+f_{1} H V+f_{2} C C \\
q l t_{i n t} & =g_{0}+g_{1} H V+g_{2} C C
\end{aligned}
$$

Solving this system of equations, gives the following expressions for $y_{c}$ and $p_{m}:{ }^{23}$

$$
\begin{aligned}
y_{c}=\frac{1}{1-a_{2} e_{1} b_{1}}\left[K_{1}+\left(a_{1} d_{1} c_{1}+\right.\right. & \left.a_{2} e_{1} b_{2} c_{1}+a_{2} e_{2}+a_{3} f_{1}+a_{4} g_{1}\right) H V \\
& \left.+\left(a_{1} d_{1} c_{2}+a_{2} e_{1} b_{2} c_{2}+a_{2} e_{3}+a_{3} f_{2}+a_{4} g_{2}\right) C C\right]
\end{aligned}
$$

$$
\begin{aligned}
p w b_{m}=\frac{b_{1}}{1-a_{2} e_{1} b_{1}}\left[K_{2}+\left(a_{1} d_{1} c_{1}+\right.\right. & \left.\frac{b_{2} c_{1}}{b_{1}}+a_{2} e_{2}+a_{3} f_{1}+a_{4} g_{1}\right) H V \\
& \left.+\left(a_{1} d_{1} c_{2}+\frac{b_{2} c_{2}}{b_{1}}+a_{2} e_{3}+a_{3} f_{2}+a_{4} g_{2}\right) C C\right]
\end{aligned}
$$

where $K_{1}$ and $K_{2}$ are constants. To be able to determine the signs of the derivatives of $y_{c}$ and $p w b_{m}$ with respect to $H V$ and $C C$, we need to know the signs of the underlying parameters. Table 8 summarizes these signs, which are either based on an assumption ("A") or on a result reported in Table 7 ("T7"). We assume that $a_{2} e_{1} b_{1}<1$. The signs of the derivatives are then determined by the expressions in parentheses.

\footnotetext{
${ }^{23}$ The expression for $h_{m}$ is already given in equation (6) since there is no feed-back mechanism through which hours are affected by child outcomes or mother's well-being.
} 
Table 8. Signs of model parameters

\begin{tabular}{l|cccccccccccccccc}
\hline parameter & $a_{1}$ & $a_{2}$ & $a_{3}$ & $a_{4}$ & $b_{1}$ & $b_{2}$ & $c_{1}$ & $c_{2}$ & $d_{1}$ & $e_{1}$ & $e_{2}$ & $e_{3}$ & $f_{1}$ & $f_{2}$ & $g_{1}$ & $g_{2}$ \\
\hline sign & + & + & + & + & + & - & - & + & - & + & + & - & + & + & $+/ 0$ & $+/ 0$ \\
source & $\mathrm{A}$ & $\mathrm{A}$ & $\mathrm{A}$ & $\mathrm{A}$ & $\mathrm{A}$ & $\mathrm{A}$ & $\mathrm{T} 7$ & $\mathrm{~T} 7$ & $\mathrm{~A}$ & $\mathrm{~A}$ & $\mathrm{~T} 7$ & $\mathrm{~T} 7$ & $\mathrm{~A}$ & $\mathrm{~A}$ & $\mathrm{~A}$ & $\mathrm{~A}$ \\
\hline
\end{tabular}

The sign of the derivative of $y_{c}$ with respect to $H V$ is determined by five terms. With the parameters signs in Table 8, the first four terms are positive and the last term is nonnegative. Hence, home visits have a beneficial impact on child outcomes. This is also what we find in Tables 5 and 6 . The sign of the derivative of $y_{c}$ with respect to $C C$ is also determined by five terms. Given the parameter signs in Table 8 , the first three terms are negative, the fourth is positive, and the fifth is non-negative. When $a_{1} d_{1} c_{2}+a_{2} e_{1} b_{2} c_{2}+$ $a_{2} e_{3}<-a_{3} f_{2}-a_{4} g_{2}$, this derivative is negative, consistent with some of our findings in Tables 5 and 6 that child care centers have a negative impact on child outcomes. The first channel through which this operates is the increase in working hours of the mother, which by assumption reduces the amount of time the mother spends with her child, thereby reducing this input. The second channel is that an increase in mother's working hours increases mother's stress, which in turn has a negative impact of the quality of mother's time input. The third channel is that child care centers have a negative impact on mother's parenting quality. Together these three channels are apparently strong enough to undo any positive impact that the quantity and the quality of child care centers have on the outcomes of the child.

The sign of the derivative of mother's psychological well-being with respect to home visits is determined by five underlying terms. The signs of the first four terms are positive and the sign of the last term is non-negative. This is consistent with our finding that mother's psychological well-being increases when her child is enrolled in a home visit program. Also the sign of the derivative of mother's psychological wellbeing with respect to child care centers is determined by five underlying terms. The first three are negative, the fourth positive and the last one non-negative. Whenever $a_{1} d_{1} c_{2}+\frac{b_{2} c_{2}}{b_{1}}+a_{2} e_{3}<-a_{3} f_{2}-a_{4} g_{2}$, the negative terms dominate the non-negative terms and mother's psychological well-being is harmed when her child is enrolled in a child care center. This is what we find in Table 7. The first mechanism through which this operates is that child care centers increase mother's working hours, this reduces the time input in the child and thereby the child's outcomes. Lower child outcomes harm mother's psychological well-being. The second mechanism is direct, working reduces mother's well-being. Finally, we find that mother's parenting quality deteriorates when the child is enrolled in a child care center. This is stressful for mothers, through the lower child outcomes that this causes. As it turns out, the three mechanisms are together strong enough 
to offset any positive impact that child care centers may have on the mother's well-being through the increase in child outcomes.

The analysis in this section highlights the mechanisms that cause the very different effects we find of home visits and child care centers on child outcomes and mother's psychological well-being. Home visits improve mothers' parenting styles while child care centers worsen these. Child care centers increase working hours which causes stress in mothers, both directly and through the negative impact this has on child outcomes. Home visits instead reduce working hours.

\section{Conclusions}

The evidence on the effects of early childhood interventions in the context of developing countries is thin. In this paper we provide evidence on the impact of child care centers and home visits on a broad range of outcomes: children's cognitive and motor development, children's health, parenting styles, mothers' labor supply and income and mothers' psychological well-being. Home visits and child care centers are both evaluated against no intervention through a regression discontinuity design, and are compared directly by combining the regression discontinuity design with a difference-in-differences approach (and matching).

Our results show that home visits have a positive impact on children's cognitive and motor outcomes, whereas child care centers have no or possibly a negative impact on these outcomes. Home visits have a positive impact on children's health by reducing the probability to have anemia by one third. Child care centers result in children being underweight more often. Furthermore, home visits reduce mothers' stress and depression symptoms and make them more responsive towards their children. Child care centers do the opposite: they harm mothers' psychological well-being and reduce responsiveness. Finally, child care centers increase mothers' labor market participation and family income, while home visits reduce mothers' labor market participation but leave family income unaffected. The two types of interventions thus represent a trade-off between child outcomes and mother's psychological well-being on the one hand, and labor market participation and family income on the other hand. For a choice between the two programs it is also important that the per child cost of a child care center is almost five times as high than the per child cost of home visits.

Our findings are consistent with a framework in which children's outcomes are determined by the quantity and the quality of time spent with them by the mother and by the early childhood program, and in which the psychological well-being of the mother is determined by her working hours and the outcomes of the child. In this framework, 
child outcomes and mother's psychological well-being are adversely affected by child care centers through the negative effect these centers have on the mother's parenting style and through the increase of mother's working hours. Home visits do not have adverse effects since this intervention improves mother's parenting styles and reduce her working hours.

This discussion makes explicit that our findings are conditional on the quality of the early childhood interventions included in our design. We emphasize that our analysis looks at the effects of programs that were well above the minimum quality standards required to receive funding. Moreover, the home visit programs and child care centers that we evaluate are of the same quality level (measured by the scores that the proposals received in the contest for quality indicators). At the same time, lower quality of child care centers in Ecuador than those operated elsewhere might explain why we find negative effects of child care centers on children's development while studies for Norway and Germany report positive effects of child care centers on these outcomes (Havnes and Mogstad, 2011; Felfe and Lalive, 2010). Our findings for child care centers are, however, very similar to the results reported for Canada (Baker et al., 2008).

The trade-off that we identified poses a difficult choice to policy makers and funding agencies. Children and women in poor families in developing countries are both vulnerable groups. Home visits benefit children, whereas child care centers cause women to be stressed and depressed but are also likely to empower them by increasing their labor market participation. We trust that information about these conflicting interests are helpful in formulating and implementing efficient policies.

\section{References}

Almond, D. and Currie, J. (2011). Human capital development before age five. In Ashenfelter, O. and Card, D., editors, Handbook of Labor Economics, volume 4, chapter 15, pages 1315-1486. Elsevier Science Publishers B.V.

Angrist, J. D. and Lavy, V. (1999). Using Maimonides' rule to estimate the effect of class size on scholastic achievement. Quarterly Journal of Economics, 114(2):533-575.

Attanasio, O. P., Di Maro, V., and Vera-Hernandez, M. (2010). Community nurseries and the nutritional status of poor children: Evidence from Colombia. Unpublished working paper.

Attanasio, O. P. and Vera-Hernandez, M. (2004). Medium and long run effects of nutrition and child care: Evaluation of a community nursery programme in rural Colombia. Technical report. 
Baker, M., Gruber, J., and Milligan, K. (2008). Universal child care, maternal labor supply, and family well-being. Journal of Political Economy, 116:709-745.

Behrman, J., Cheng, Y., and Todd, P. (2004). Evaluating preschool programs when length of exposure to the program varies: A nonparametric approach. Review of Economics and Statistics, 86:108-132.

Berlinski, S. and Galiani, S. (2007). The effect of a large expansion of pre-primary school facilities on preschool attendance and maternal employment. Labour Economics, 14:665-680.

Berlinski, S., Galiani, S., and Gertler, P. (2008). The effect of pre-primary education on primary school performance. Journal of Public Economics, 93:219-234.

Currie, J. (2001). Early childhood interventions. Journal of Economic Perspectives, 15(2):213-238.

Currie, J. and Thomas, D. (1995). Does Head Start make a difference? American Economic Review, 85(3):341-364.

Datta Gupta, N. and Simonsen, M. (2010). Non-cognitive child outcomes and universal high quality child care. Journal of Public Economics, 94:30-43.

Engle, P. L., Black, M. M., Behrman, J. R., Cabral de Mello, M., Gertler, P. J., Kapirini, L., Martrell, R., and Eming Young, M. (2007). Strategies to avoid the loss of developmental potential in more than 200 million children in the developing world. The Lancet, 369:229-242.

Felfe, C. and Lalive, R. (2010). The how does early child care affect child development? Learning from the children of German unification. Unpublished working paper.

Fitzpatrick, M. D. (2010). Preschoolers enrolled and mothers at work? The effects of universal prekindergarten. Journal of Labor Economics, 28:51-85.

Gormley, Jr., W. and Gayer, T. (2006). Promoting school readiness in Oklahoma: An evaluation of Tulsa's pre-K program. The Journal of Human Resources, 40:533-558.

Grantham-McGregor, S., Cheung, Y. B., Cueto, S., Glewwe, P., Richter, L., and Strupp, B. (2007). Developmental potential in the first 5 years for children in developing countries. The Lancet, 369:60-70.

Havnes, T. and Mogstad, M. (2011). No child left behind: Subsidized child care and children's long-run outcomes. American Economic Journal: Economic Policy, 3:97129. 
Imbens, G. and Lemieux, T. (2008). Regression discontinuity designs: A guide to practice. Journal of Econometrics, 142:615-635.

Magnuson, K. A., Ruhm, C., and Waldfogel, J. (2007). Does pre-kindergarten improve school preparation and performance? Economics of Education Review, 26:33-51.

McKay, H., Sinisterra, L., McKay, A., Gomez, H., and Lioreda, P. (1978). Improving cognitive ability in chronically deprived children. Science, 200:270-278.

Oosterbeek, H., Ponce, J., and Schady, N. (2008). The impact of cash transfers on school enrollment: Evidence from Ecuador. Technical report, Tinbergen Institute Discussion Papers.

Powell, C., Baker-Henningham, H., Walker, S., Gernay, J., and Grantham-McGregor, S. (2004). Feasibility of integrating early stimulation into primary care for undernourished Jamaican children: cluster randomised controlled trial. British Medical Journal, 329:89.

Waber, D. P., Vuori-Christiansen, L., Ortiz, N., Clement, J. R., Christiansen, N. E., Mora, J. O., Reed, R. B., and Herrera, M. (1981). Nutritional supplementation, maternal education and cognitive development of infants at risk of malnutrition. American Journal of Clinical Nutrition, 34:807-813.

Wong, V. C., Cook, T. D., Barnett, W., and Jung, K. (2008). An effectiveness-based evaluation of five state pre-kindergarten programs. Journal of Policy Analysis and Management, 27:122-154. 


\section{Appendix}

Table A1: Linear probability model for being listed for home visits vs child care centers

\begin{tabular}{lrcc} 
& coefficient & & s.e. \\
\hline Boy & 0.008 & & $(0.017)$ \\
Age & -0.003 & $* * *$ & $(0.001)$ \\
Household size & -0.024 & $* *$ & $(0.012)$ \\
Urban & 0.126 & $* * *$ & $(0.021)$ \\
Cash transfer & 0.049 & $* * *$ & $(0.019)$ \\
Wealth index & 0.011 & $* * *$ & $(0.004)$ \\
Mother's age & 0.001 & & $(0.001)$ \\
Schooling mother & 0.012 & $* * *$ & $(0.003)$ \\
Schooling head/10 & -0.002 & & $(0.024)$ \\
Language score mother/10 & 0.002 & & $(0.005)$ \\
Father present & -0.016 & & $(0.026)$ \\
Mother present & -0.029 & & $(0.050)$ \\
Indigenous & -0.052 & $* * *$ & $(0.019)$ \\
Number of adolescents in household & -0.019 & $* *$ & $(0.008)$ \\
Number of adults in household & 0.010 & & $(0.018)$ \\
Number of old people in the household & -0.018 & & $(0.041)$ \\
Mother is illiterate & 0.023 & & $(0.031)$ \\
$R^{2}$ & 0.09 & & \\
$N$ & 2707 & & \\
\hline
\end{tabular}

Note: Robust standard errors in parentheses. $* * * * * *$ indicates significance at the $1 \% / 5 \%$-level. 


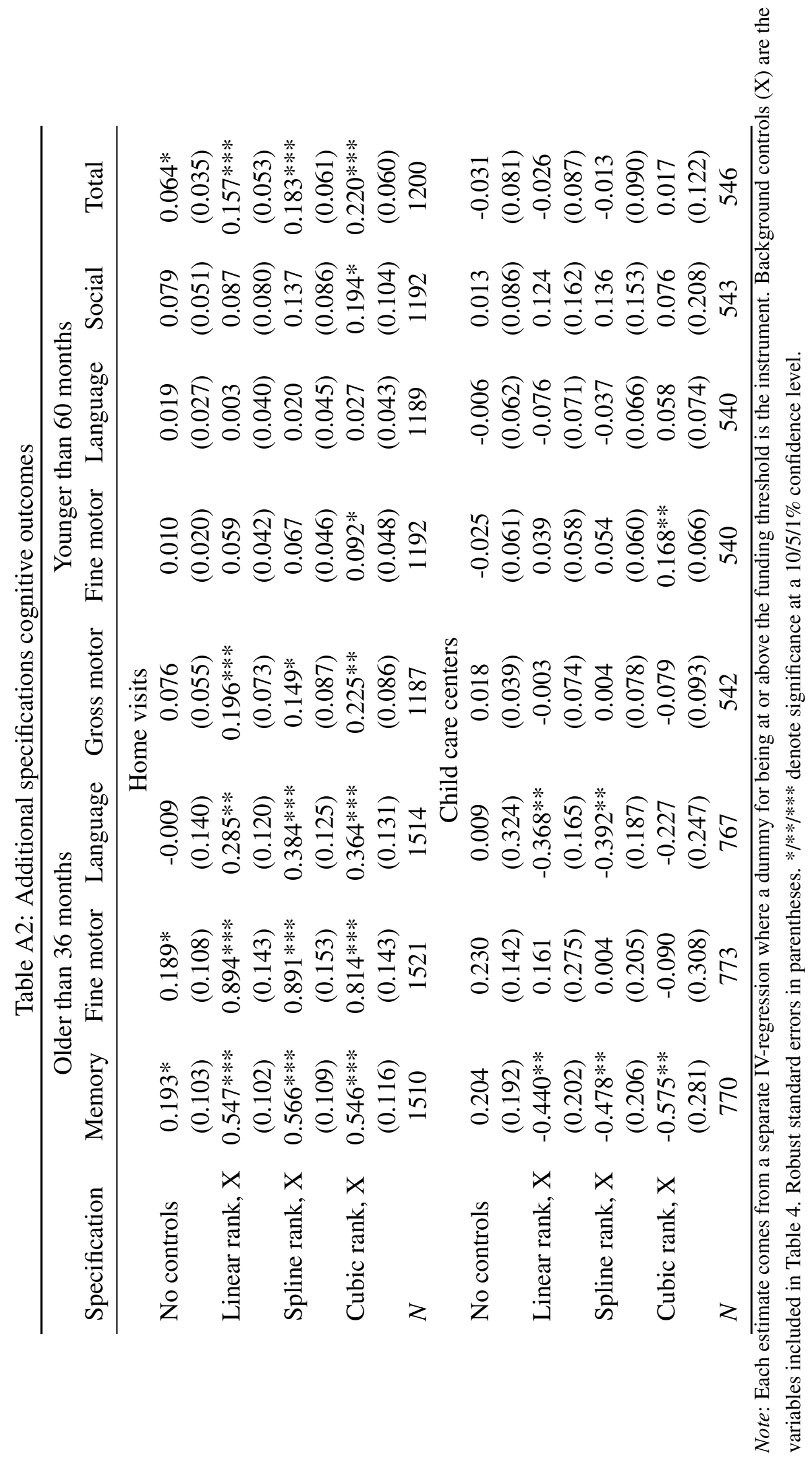


Table A3: Additional specifications health outcomes

\begin{tabular}{|c|c|c|c|}
\hline Specification & $\mathrm{a}$ & $\begin{array}{l}\text { Under } \\
\text { weight }\end{array}$ & $\begin{array}{l}\text { Below } \\
\text { height }\end{array}$ \\
\hline \multicolumn{4}{|c|}{ Home visits } \\
\hline No controls & $\begin{array}{l}-0.068 \\
(0.046)\end{array}$ & $\begin{array}{c}0.016 \\
(0.015)\end{array}$ & $\begin{array}{c}0.082 * * \\
(0.039)\end{array}$ \\
\hline Linear rank, $\mathrm{X}$ & $\begin{array}{r}-0.21 \\
(0.0\end{array}$ & $\begin{array}{c}0.028 \\
(0.031)\end{array}$ & $\begin{array}{c}0.114 * * \\
(0.050)\end{array}$ \\
\hline Spline rank, $\mathrm{X}$ & $\begin{array}{c}-0.188 * * * \\
(0.066)\end{array}$ & $\begin{array}{c}0.029 \\
(0.029)\end{array}$ & $\begin{array}{c}0.090 \\
(0.054)\end{array}$ \\
\hline Cubic rank, $\mathrm{X}$ & $\begin{array}{r}-0.1 \\
(0.1\end{array}$ & $\begin{array}{c}0.026 \\
(0.031)\end{array}$ & $\begin{array}{c}0.005 \\
(0.066)\end{array}$ \\
\hline$N$ & 1658 & 1787 & 1769 \\
\hline \multicolumn{4}{|c|}{ Child care centers } \\
\hline No controls & $\begin{array}{c}0.115 * * * \\
(0.035)\end{array}$ & $\begin{array}{l}0.043^{*} \\
(0.025)\end{array}$ & $\begin{array}{c}0.189 * * \\
(0.082)\end{array}$ \\
\hline Linear rank, $\mathrm{X}$ & $\begin{array}{l}-0.026 \\
(0.101)\end{array}$ & $\begin{array}{c}0.088 * * \\
(0.037)\end{array}$ & $\begin{array}{l}-0.021 \\
(0.095)\end{array}$ \\
\hline Spline rank, $\mathrm{X}$ & $\begin{array}{l}-0.021 \\
(0.100)\end{array}$ & $\begin{array}{c}0.091 * * \\
(0.034)\end{array}$ & $\begin{array}{c}0.005 \\
(0.077)\end{array}$ \\
\hline Cubic rank, $\mathrm{X}$ & $\begin{array}{c}0.031 \\
(0.117)\end{array}$ & $\begin{array}{c}0.095 \\
(0.065)\end{array}$ & $\begin{array}{c}0.183 \\
(0.118)\end{array}$ \\
\hline$N$ & 763 & 872 & 870 \\
\hline
\end{tabular}

Note: See the note of Table A2. 


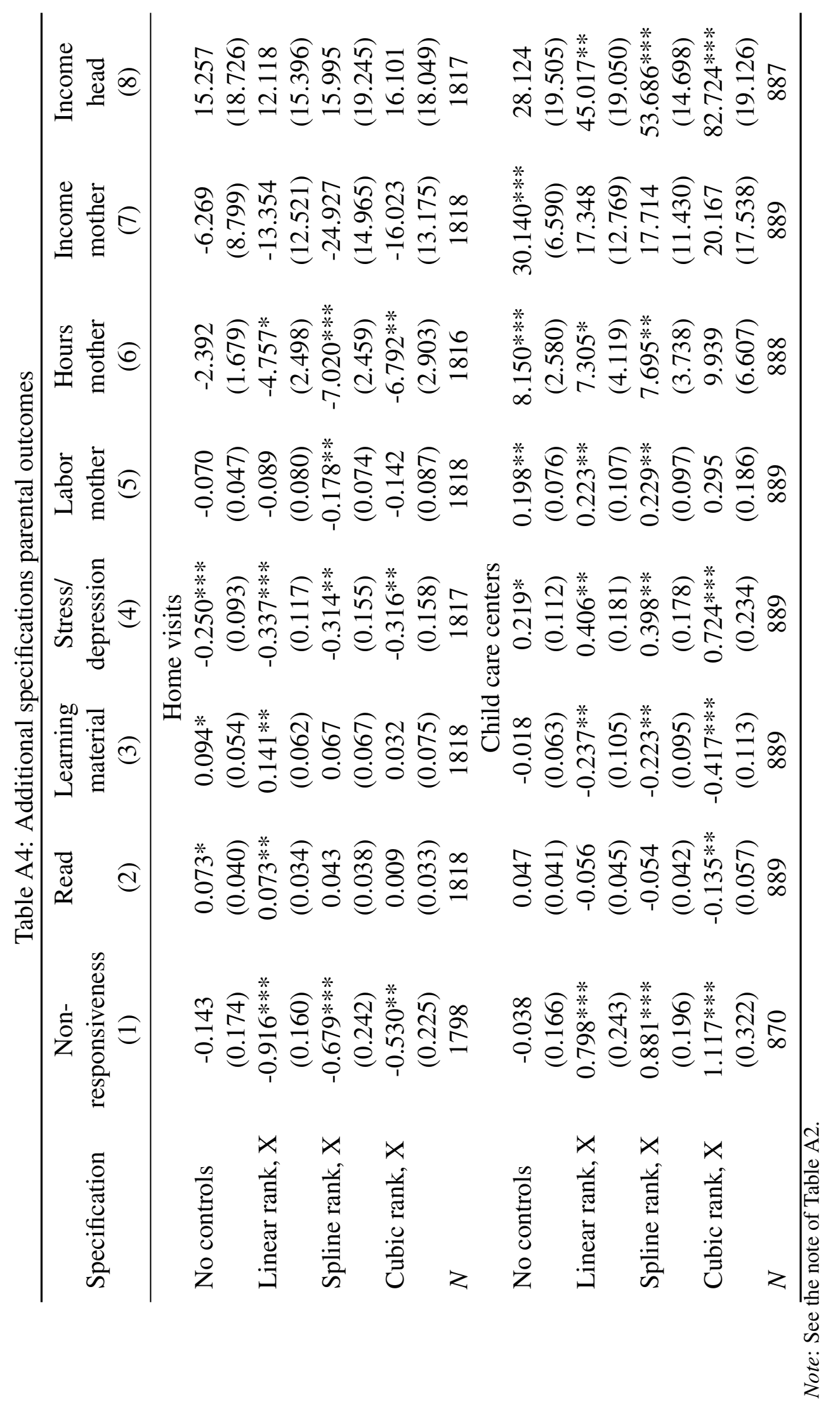

